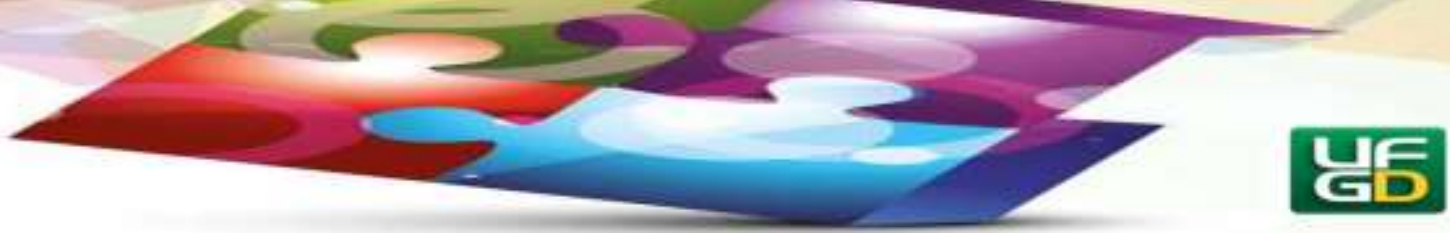

\title{
ORGANIZAÇÃO E FUNCIONAMENTO DAS CLASSES HOSPITALARES: UMA PRERROGATIVA DA EDUCAÇÃO ESPECIAL? ${ }^{1}$
}

ORGANIZATION AND FUNCTIONING OF THE HOSPITAL CLASSES: A SPECIAL EDUCATION PRERROGATIVE?

Andréia Pires Dias CLARO²

Eduardo Adão RIBEIRO ${ }^{3}$

Washington Cesar Shoiti NOZU ${ }^{4}$

\begin{abstract}
Resumo: Este trabalho objetiva, na interface das áreas da Educação e da Saúde, compreender a organização e o funcionamento das classes hospitalares, bem como a definição dos estudantes/pacientes destinados a este serviço, alocado sob a competência da Educação Especial. Metodologicamente, a pesquisa define-se como um estudo documental e bibliográfico, operacionalizado por meio de seleção de fontes, leituras e fichamentos. A classe hospitalar é conceituada como espaço destinado ao apoio pedagógico educacional aos alunos matriculados na Educação Básica e que se encontram hospitalizados. Este serviço consta no rol de atendimentos da Educação Especial por abranger necessidades específicas e educacionais especiais durante o período de hospitalização, visando o acesso aos conteúdos curriculares, de modo que o estudante possa retornar, quando possível, ao processo regular de escolarização.
\end{abstract}

Palavras-chave: Modalidades de Educação Especial. Classe Especial Hospitalar. Ensino Hospitalar.

\begin{abstract}
This paper aims, at the interface of the areas of Education and Health, to understand the organization and functioning of hospital classes, as well as the definition of students/patients destined to this servisse, allocated under the competence of Special Education. Methodologically, the research is defined as a documentary and bibliographic study, made operational through the selection of sources, readings and records. The hospital class is regarded as a space for educational pedagogical support for students enrolled in Basic Education and who are hospitalized. This service is included in the list of Special Education services because

\footnotetext{
${ }^{1}$ Trata-se de uma versão revisada e atualizada do Trabalho de Graduação - critério para a conclusão do Curso de Pedagogia, da Universidade Federal da Grande Dourados - da primeira autora, sob a coorientação do segundo autor e a orientação do terceiro autor.

${ }^{2}$ Professora da Rede Estadual de Ensino de Mato Grosso do Sul. Especialista em Libras e Educação Especial pelo Grupo Rhema Educação. Licenciada em Pedagogia pela Universidade Federal da Grande Dourados. Técnica em Enfermagem pela Vital Brasil Dourados. E-mail: andreiapclaro@gmail.com

${ }^{3}$ Professor da Faculdade Anhanguera de Dourados. Advogado. Mestre em Fronteiras e Direitos Humanos pela Universidade Federal da Grande Dourados. Bacharel em Direito pela Universidade Estadual de Mato Grosso do Sul. E-mail: ribeiro.edu01@gmail.com

${ }^{4}$ Professor Adjunto da Universidade Federal da Grande Dourados (UFGD). Doutor e Mestre em Educação pela UFGD. Especialista em Educação, Licenciado em Pedagogia e Bacharel em Direito pela Universidade Estadual de Mato Grosso do Sul. E-mail: WashingtonNozu@ufgd.edu.br
} 


\section{HORIZONTES - REVISTA DE EDUCAÇÃO}

it covers specific and special educational needs during the hospitalization period, aiming at accessing the curricular contents, so that the student can return, when possible, to the regular schooling process.

Keywords: Special Education Modalities. Hospital Special Class. Teaching Hospital.

\section{Introdução}

A Educação Especial tem centrado esforços, sob a perspectiva inclusiva, para promover ampla participação, nos processos de ensino e de aprendizagem, dos estudantes definidos como seu público-alvo, quais sejam as pessoas com deficiência, transtornos globais do desenvolvimento e altas habilidades/superdotação (BRASIL, 2008). A atuação da Educação Especial pode ser operacionalizada tanto em instituições de ensino, comuns ou especializadas, quanto em ambientes externos, como ocorre com as classes hospitalares (BRASIL, 2001a).

Diferente do que pode ser verificado em escolas, o foco do atendimento em ambientes hospitalares é digirido a pessoas que não necessariamente são classificadas como Público-Alvo da Educação Especial (PAEE). A classe hospitalar, portanto, constitui-se em um espaço destinado ao apoio pedagógico e como alternativa de atendimento educacional, intentando oferecer respostas às necessidades específicas e educacionais especiais, durante o período de hospitalização, de modo a proporcionar ao aluno hospitalizado o acesso aos conteúdos trabalhados em sala de aula regular, para que ele possa retornar ao ambiente escolar após a alta, sem prejuízos no aprendizado. Dessa forma, a Educação Especial tem sido convocada, nesse contexto, a assegurar suporte pedagógico, recursos e serviços educacionais especializados aos alunos hospitalizados (BRASIL, 2001a; BRASIL, 2002; FONSECA; ARAÚJO; LADEIRA, 2018).

No Brasil, o primeiro mapeamento sobre as classes hospitalares foi realizado no período entre julho de 1997 a fevereiro de 1998 (FONSECA, 2011). A última atualização sobre esses dados foi realizada em julho de 2014, expondo que o país conta com 155 hospitais com classes hospitalares, distribuídos por 19 estados e no distrito federal, conforme a listagem apresentada: Região Norte - total de 10 hospitais; Região Nordeste - total de 26 hospitais; Região CentroOeste - total de 26 hospitais; Região Sudeste - total de 64 hospitais; e Região Sul - total de 29 hospitais. Segundo esse levantamento, nos estados do Amazonas, Rondônia, Amapá, Piauí, 


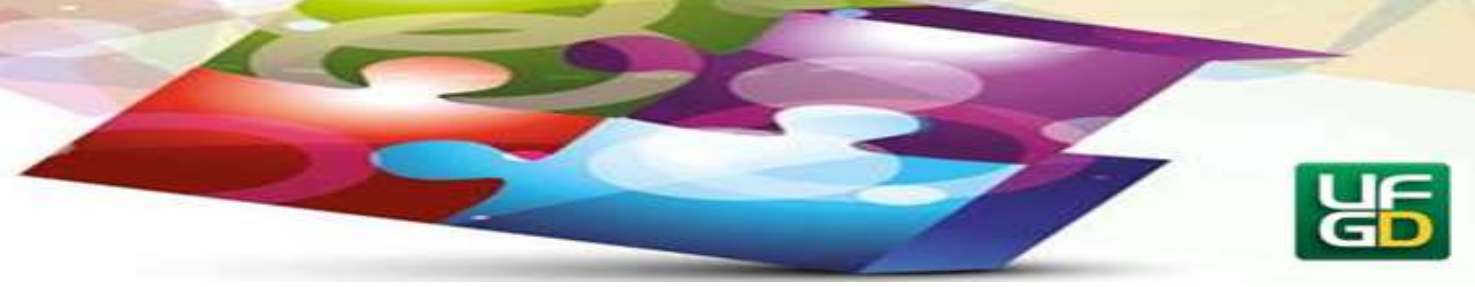

Paraíba, Pernambuco e Alagoas não há registros sobre a existência de hospitais com classe hospitalar para as crianças e/ou adolescentes internados (FONSECA, 2015).

Utilizando dados do Censo Escolar, Pacco e Gonçalves (2019a) identificaram, em 2015, a existência de 286 turmas em classes hospitalares. Nessas turmas, constataram a matrícula de 6.052 estudantes, sendo que 39 deles faziam parte do PAEE. As autoras salientam ainda as disparidades existentes nesses dados estatísticos, haja vista que são computadas somente as turmas e não classes hospitalares, destacando também a grande rotatividade dos alunos atendidos, o que vem a influenciar na contagem das matrículas. Dessa forma, sustentam a necessidade de novas pesquisas para compreender esse cenário.

Após mapeamento das produções científicas sobre o atendimento educacional hospitalar entre os anos de 2013 e 2018, Pacco e Gonçalves (2019b) identificaram a existência de 233 trabalhos, dentre os quais, $21,4 \%$ discorre sobre organização e funcionamento da classe hospitalar.

Assim, destaca-se a relevância acadêmica de pesquisas neste campo educacional, bem como por possibilitar aos profissionais da Educação e da Saúde, aos alunos hospitalizados e suas famílias uma visão sobre as políticas de organização e de funcionamento de classes hospitalares, além de instigar um olhar crítico sobre a competência da Educação Especial diante dessa demanda.

Nesta perspectiva, o presente artigo objetiva, na interface das áreas da Educação e da Saúde, compreender a organização e o funcionamento das classes hospitalares, bem como a definição dos estudantes/pacientes destinados a este serviço, alocado sob a competência da Educação Especial.

Metodologicamente, a pesquisa desenvolveu-se por meio de estudo documental e bibliográfico, operacionalizado por meio de seleção de fontes, leituras e fichamentos. Recorreuse a essa abordagem pela vantagem de permitir a cobertura de uma gama de informações amplamente acessíveis (GIL, 2010), ultilizando principalmente documentos políticonormativos do Ministério da Educação (MEC) e, ainda, artigos de periódicos e capítulos de livros.

Este artigo foi organizado em duas seções. A primeira aborda aspectos históricos e políticos das classes hospitalares no Brasil, no bojo dos serviços de Educação Especial. A 


\section{HORIZONTES - REVISTA DE EDUCACATO}

e-ISSN: $2318-1540$

segunda dicorre sobre a organização e o funcionamento das classes hospitalares. Por fim, são tecidas algumas considerações sobre a temática.

\section{Apontamentos Histórico-Políticos das Classes Hospitalares no Brasil}

Na história da educação, a classe hospitalar tem sua origem na França, em 1935, e, posteriormente, na Alemanha e Estados Unidos. No Brasil, iniciou-se em 1950, com a classe hospitalar no Hospital Jesus, localizado no Rio de Janeiro. No entanto, há registros que em 1600, ainda no Brasil Colônia, havia atendimento escolar aos deficientes físicos na Santa Casa de Misericórdia em São Paulo (OLIVEIRA, 2013).

$\mathrm{O}$ atendimento à criança hospitalizada avançou de modo quase imperceptível após a Segunda Guerra Mundial, quando alguns países da Europa receberam, crianças mutiladas e com doenças contagiosas como a tuberculose, por exemplo (VASCONCELOS, 2008). É nesse contexto também que, em 1948, é publicada, pela Organização das Nações Unidas, a Declaração Universal dos Direitos Humanos, cuja defesa da educação e da saúde, como basilares para todas as pessoas, passa a ser disseminada internacionalmente.

Em face dessas influências, a Constituição Federal Brasileira de 1988 garante, dentre outros, os direitos fundamentais como a educação e a saúde. Ambos devem ser assegurados mediante políticas sociais que visem ao acesso universal e igualitário às ações e serviços para sua proteção, atendendo às necessidades dos sujeitos, com qualidade e integralidade, em suas condições e limitações específicas decorrentes de tratamento de saúde física e mental, na internação ou domiciliar, sendo esta, uma das diretrizes do Sistema Único de Saúde, definido em consonância com os Artigos 197 e 198 desse dispositivo legal (BRASIL, 1988).

Até 1988, a educação da pessoa com deficiência era abordada no âmbito da Assistência Social, mudando então a partir da atual Constituição, a qual estabelece como dever do Estado oferecer o Atendimento Educacional Especializado (AEE), preferencialmente na rede regular de ensino (BRASIL, 1988).

Em que pesem as contribuições da Constituição Federal na garantia do direito à educação das pessoas com deficiência, as políticas nessa área foram orientadas pela perspectiva da integração, a qual somente deixou de prevalecer na década de 2000. 


\section{HORIZONTES - REVISTA DE EDUCACATO}

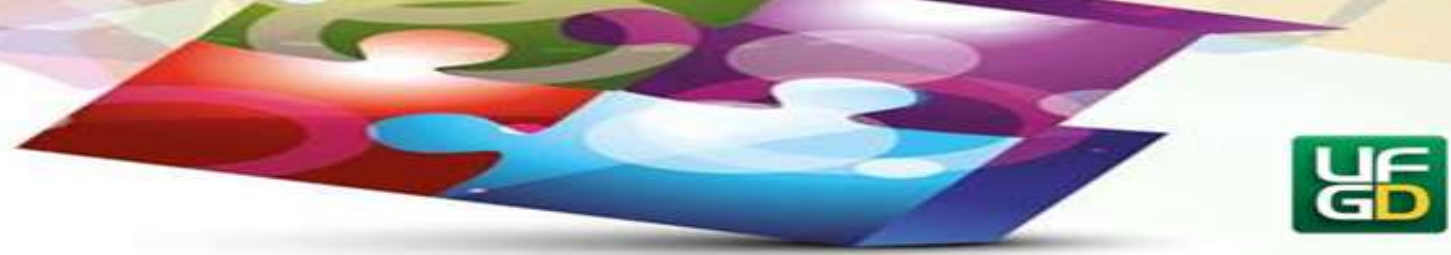

A integração pautava-se no modelo médico da deficiência, centrado em promover mudanças nos próprios sujeitos, de forma que estes adquirissem as condições necessárias para se inserirem nas estruturas sociais, conforme os padrões estabelecidos como "normais" (NOZU, 2014).

Em 1994, a Política Nacional de Educação Especial (PNEE), fundamentada no paradigma da integração, sugeria a inserção nas classes comuns apenas de estudantes "portadores de necessidades educacionais especiais" que estiverem no mesmo ritmo e os estudantes sem deficiência do ensino regular. Assim, atribuía " [...] ao aluno com deficiência a responsabilidade pelo seu sucesso ou fracasso na trajetória escolar" (NOZU, 2014, p. 47). Também neste documento, havia previsão do ensino em ambientes hospitalares, o qual deveria ser realizado em salas organizadas no próprio edifício do hospital ou mesmo no leito, caso o aluno não pudesse se locomover (BRASIL, 1994).

A educação em hospital aparece como um serviço a partir da PNEE, com efeito de classe hospitalar. O mesmo documento reitera que esta oferta educacional não se resume somente às crianças com deficiências e transtornos do desenvolvimento, como especificado, mas abrange também aquelas em situação de risco ao desenvolvimento, como é o caso da internação hospitalar (CECCIM, 1999).

Em 1996, é publicada a Lei de Diretrizes e Bases da Educação Nacional (LDBEN), que, em capítulo próprio, irá tratar da Educação Especial, definida neste dispositivo como uma modalidade de educação escolar oferecida preferencialmente na rede regular de ensino, para educandos PAEE.

A LDBEN irá assegurar métodos, currículos, recursos e organização específica para atendimento dos alunos PAEE, bem como preconizar a matrícula desse alunado no ensino regular, permitindo, contudo, a manutenção das classes, escolas e serviços especializados quando, em função das condições do aluno, a primeira opção não for possível (BRASIL, 1996). Assim, observa-se que, nesse documento, ao manter como foco a condição do aluno, é mantida a perspectiva integracionista da educação, o que, para Mantoan (2003), é a continuação da segregação e discriminação desses estudantes dentro e fora da sala de aula.

No que concerne às classes hospitalares, é oportuno sinalizar que a Lei n. 13.716, de 24 de setembro de 2018 modifica a LDBEN/1996, acrescentando o seguinte artigo: 


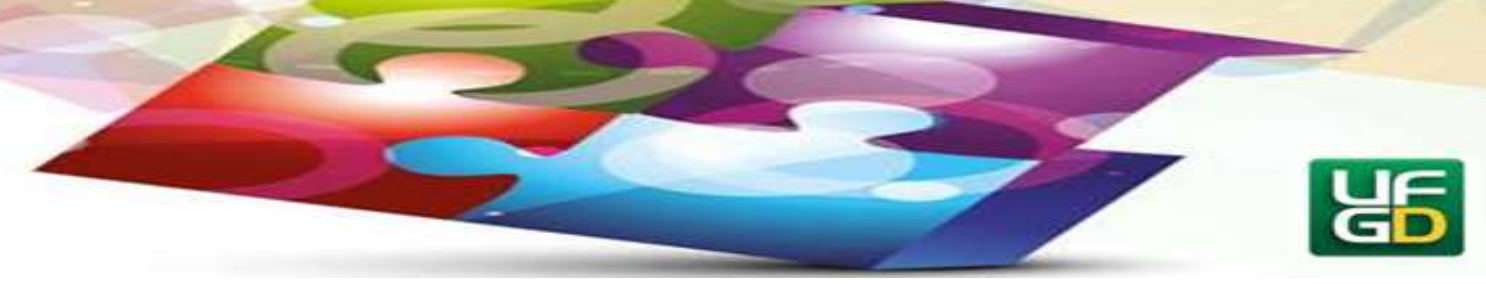

Art. $4^{\text {o }}$-A. É assegurado atendimento educacional, durante o período de internação, ao aluno da educação básica internado para tratamento de saúde em regime hospitalar ou domiciliar por tempo prolongado, conforme dispuser o Poder Público em regulamento, na esfera de sua competência federativa (BRASIL, 2018).

Esta alteração na LDBEN/1996 assegura atendimento educacional aos alunos da Educação Básica (a qual compreende a Educação Infantil, o Ensino Fundamental e o Ensino Médio) que estejam em tratamento de saúde em regime hospitalar (BRASIL, 2018).

As Diretrizes Nacionais para a Educação Especial na Educação Básica, instituídas pela Resolução CNE/CEB n. 2, de 11 de setembro de 2001, preveem que o atendimento educacional especializado pode ocorrer para além do espaço escolar, sendo uma dessas possibilidades a classe hospitalar, conceituada como "[...] serviço destinado a prover, mediante atendimento especializado, a educação escolar a alunos impossibilitados de frequentar as aulas em razão de tratamento de saúde que implique internação hospitalar ou atendimento ambulatorial" (BRASIL, 2001a, p. 51).

Com essas diretrizes, torna-se imprescindível um melhor conhecimento da realidade do atendimento escolar em ambiente hospitalar, para construir subsídios nas interfaces da Educação e da Saúde que oportunizem o acesso ao conhecimento curricular pelo aluno/paciente.

O paradigma da inclusão, já tangenciado nas Diretrizes Nacionais para a Educação Especial na Educação Básica (BRASIL, 2001a), ao contrário da integração, baseia-se no modelo social da deficiência, deslocando o foco do indivíduo para a estrutura social e exigindo desta a derrubada de barreiras que impossibilitam a plena participação do PAEE (NOZU, 2014). Nessa direção, busca-se um reconhecimento das diferenças como parte da sociedade, bem como a necessidade de mudanças do meio social para promover educação de qualidade a todas as pessoas, ao longo de suas vidas (MENDES, 2006).

O marco da inclusão, no Brasil, dar-se-á com a Política Nacional de Educação Especial na Perspectiva da Educação Inclusiva (PNEEPEI), que postula o direcionamento das matrículas de alunos PAEE nas escolas comuns do ensino regular, por meio da concepção de direitos humanos que trata a igualdade e as diferenças como elementos indissociáveis na formação do ser humano. Este documento emerge, portanto, de encontro com as práticas de exclusão que ocorrem dentro e fora da escola, propondo maior equidade no ambiente educacional (BRASIL, 


\section{HORIZONTES - REVISTA DE EDUCAÇÃO}

e-ISSN: 2318-1540

2008). Sob o viés da perspectiva inclusiva, as classes hospitalares são previstas no conjunto dos serviços e recursos da Educação Especial (BRASIL, 2008).

Considerando esses movimentos da Educação Especial, nota-se que as políticas sociais estão sendo constantemente modificadas para que, de fato, ocorra a inclusão de todos, considerando para tanto, suas diferenças, particularidades e possibilidades de aprendizado. Isto não é diferente em questões ligadas à Saúde, como é possível notar em relação ao atendimento hospitalar.

Com a política de humanização da assistência hospitalar, criada também em 2001, a importância da classe hospitalar na atuação sistemática junto aos alunos/pacientes foi reessaltada. Neste sentido, essa política traz enquanto objetivos: difundir uma nova cultura de humanização na rede hospitalar pública brasileira; melhorar a qualidade e a eficácia da atenção dispensada aos usuários dos hospitais públicos no Brasil; capacitar os profissionais dos hospitais para um novo conceito de assistência à saúde que valorize a vida humana e a cidadania; conceber e implantar novas iniciativas de humanização dos hospitais que venham a beneficiar os usuários e os profissionais de saúde; fortalecer e articular todas as iniciativas de humanização já existentes na rede hospitalar pública; estimular a realização de parcerias e intercâmbio de conhecimentos e experiências nesta área; desenvolver um conjunto de indicadores de resultados e sistema de incentivos ao tratamento humanizado; modernizar as relações de trabalho no âmbito dos hospitais públicos, tornando as instituições mais harmônicas e solidárias, de modo a recuperar a imagem pública dessas instituições junto à comunidade (BRASIL, 2001b).

Em que pese o atendimento em classe hospitalar ser vinculado à Educação Especial, no que compete à sua organização, cumpre destacar que seu público compreende não só o PAEE que esteja hospitalizado, mas também quaisquer outros estudantes que necessitem de continuidade em seus estudos nesse ambiente por conta de internação (BRASIL, 2001a; 2018).

Ao pensar nessa forma organizacional, entretanto, pode-se questionar sob qual concepção de deficiência está fundada. França (2013) sustenta que a ideia de deficiência enquanto fenômeno exclusivamente biológico, desconsiderando as interações e barreiras sociais, caracteriza o modelo médico da deficiência. De acordo com essa lógica, ela seria decorrente de uma lesão que advém de alguma doença, gerando, consequentemente, desvantagens sociais. Essa concepção, no seio da Educação Especial, vem sendo 


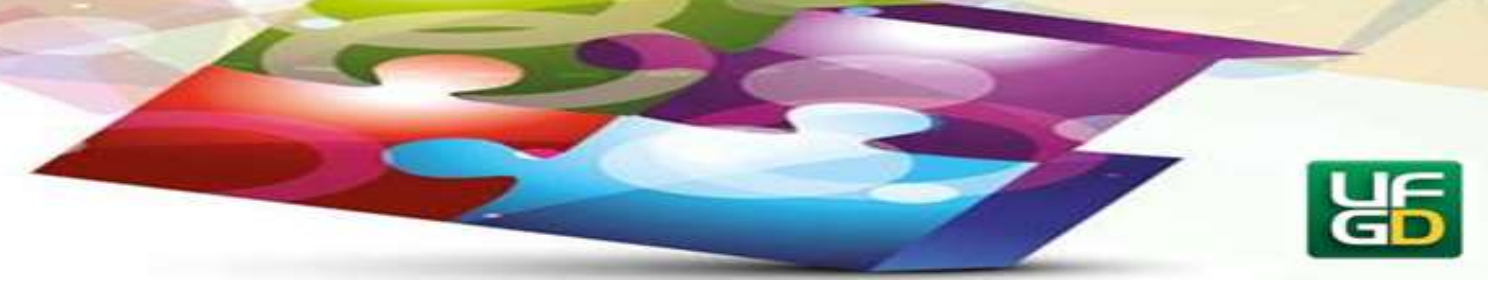

problematizada ao menos desde a década de 1960, com o delineamento do modelo social da deficiência, o qual busca desvincular a ideia de deficiência como doença, defendendo que ela é algo relacional entre o sujeito e o meio em que vive. É caracterizado também por centrar a necessidade de intervenções na sociedade para fins de eliminação ou diminuição das barreiras que impedem a plena participação das pessoas com deficiência.

Gaudenzi e Ortega (2016) discutem a relação entre deficiência e autonomia, sendo que esta é o que traça a fronteira entre o normal ou meramente atípico e o patológico. Assim, se uma pessoa não consegue cumprir, por si mesma, suas atividades vitais, tem por prejudicada o exercício de uma identidade social de sujeito livre e autônomo. Há, portanto, uma supervalorização da individualidade em oposição a um "viver coletivo".

Assim, a permanência da classe hospitalar em estreita ligação à Educação Especial, pode contribuir para reforçar a concepção médica da deficiência nesse campo, uma vez que associa quase de maneira imediata os estudantes com algum tipo de enfermidade aos cuidados da Educação Especial.

Atualmente, nem mesmo a saúde é restrita a uma condição estritamente biológica. A Organização Mundial da Saúde (OMS) define a saúde "como um completo bem-estar físico, social e mental e não apenas ausência de doenças" (OMS, 1978). Sendo assim, tanto a criança quanto o adolescente continuam em pleno processo de desenvolvimento, necessitando de uma educação comprometida não só com a sua formação acadêmica, mas também com sua inclusão social.

No contexto educacional, o direito à saúde deve ser garantido mediante políticas econômicas e sociais que visem ao acesso universal e igualitário às ações e serviços para sua recuperação e proteção, atendendo suas necessidades com qualidade e integralidade em suas condições e limitações específicas decorrentes de tratamento de saúde física e mental, na internação ou domiciliar (BRASIL, 1988).

Isto posto, a educação dentro do contexto hospitalar pode ser reconhecida como um dos fatores que integram o bem-estar de uma pessoa. Neste sentido, o papel do profissional pedagogo está além de transmitir conhecimentos, devendo refletir que a saúde não é somente condição física, mas um conjunto de situações que proporcionam uma vida plena para o indivíduo. 


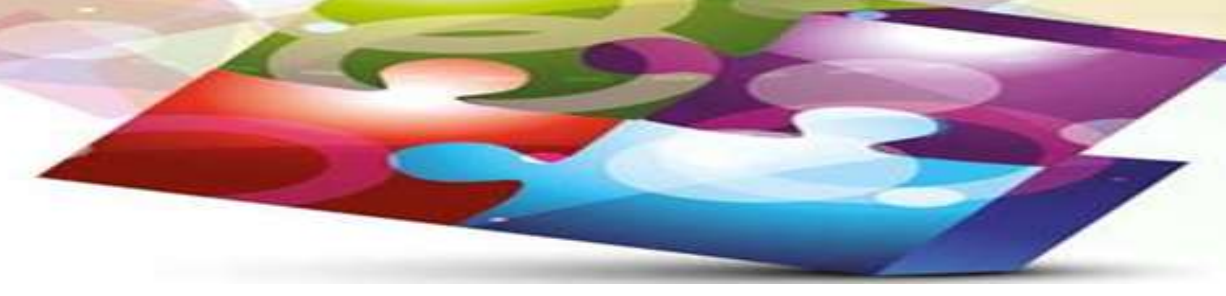

\section{Organização e Funcionamento das Classes Hospitalares}

Para a pessoa hospitalizada, o tratamento de saúde não envolve apenas os aspectos biológicos tradicionalmente conhecidos como assistência médica à enfermidade; abarca outros aspectos de suma importância ao internado. Sendo assim, a assistência hospitalar tem que abranger cuidados que assegurem o acesso ao lazer, ao convívio com o meio externo, às informações sobre seu processo de cura e cuidados terapêuticos e ainda ao seu exercício intelectual (FONSECA, 1996).

Quando os estudantes estão impossibilitados de frequentar a escola, durante o período de internação, há uma necessidade de formas alternativas de organização e oferta de ensino de modo a cumprir com os direitos à educação e à saúde, objetivando a inclusão e contribuindo para a humanização da assistência hospitalar.

A realidade da pessoa hospitalizada não a impede de ter novas experiências e de adquirir novos conhecimentos, as aulas ministradas que consideram às especificidades do aluno/paciente pode gerar contribuições no tratamento, tais como “[...] diminuir o trauma hospitalar trazendo para o hospital uma parte da vida, no caso a escola, proporcionar condições para a continuidade e alcance da terminalidade escolar, adequada às características individuais" (GONÇALVES; MANZINI, 2011, p. 4).

Neste sentido, reitera-se a previsão de que o atendimento educacional será feito em classes, escolas ou serviços especializados sempre que, em função das condições específicas dos alunos, não for possível a sua integração nas classes comuns de ensino regular (BRASIL, 1996). Conforme as Diretrizes Nacionais para a Educação Especial na Educação Básica, devese priorizar a continuidade no processo de aprendizagem em ambiente hospitalar, amparando seu retorno ao ambiente escolar (BRASIL, 2001a). Assim, as classes hospitalares devem:

[...] dar continuidade ao processo de desenvolvimento e ao processo de aprendizagem de alunos matriculados em escolas da Educação Básica, contribuindo para seu retomo e reintegração ao grupo escolar; e desenvolver currículo flexibilizado com crianças, jovens e adultos não matriculados no sistema educacional, facilitando seu posterior acesso à escola regular (BRASIL, 2001a). 


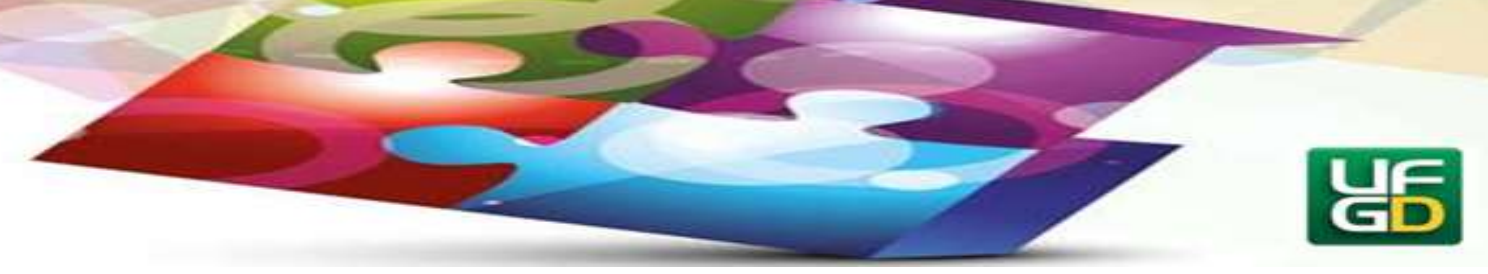

Em consonância com estas Diretrizes, os sistemas de ensinos, em articulação com os sistemas de saúde, devem organizar esse processo de atendimento, mediante políticas econômicas e sociais que visem ao acesso universal e igualitário às ações e aos serviços, tanto para a sua promoção, quanto para a sua proteção e recuperação.

Paula, Zaias e Silva (2015) afirmam que os fundamentos que sustentam o atendimento hospitalar objetivam reforçar a garantia do direito à educação, haja vista que as pessoas em situação de enfermidade não necessitam ter seus estudos paralizados em virtude de sua internação. Entretanto, as autoras defendem que esse direito, apesar de constar em diversas legislações, ainda mostra-se desconhecido por parte da população e com difícil viabilização em decorrência de processos burocráticos.

O MEC, ao perceber a necessidade de uma estruturação do sistema de atendimento educacional em ambientes hospitalares e outras instituições que não seja a escola, elaborou o documento "Classe hospitalar e atendimento pedagógico domiciliar: orientações e estratégias" (BRASIL, 2002), que dispõe sobre a organização e o funcionamento administrativo das classes hospitalares. Este documento apresenta estratégias e orientações para promoção do atendimento pedagógico em ambientes hospitalares, com o intuito de assegurar o acesso à Educação Básica e atenção às necessidades educacionais especiais, de modo a contribuir para a construção de conhecimentos dos educandos atendidos nesse ambiente (BRASIL, 2002).

Um de seus conteúdos trata das condições e limitações específicas que decorrem de tratamentos de saúde física e mental, seja na circunstância de internação, como tradicionalmente conhecida, seja na circunstância do atendimento em hospital-dia e hospital-semana, seja no próprio domicílio ou, ainda, em serviços ambulatoriais de atenção integral à saúde mental (BRASIL, 2002).

As salas onde serão realizadas atividades pedagógicas deverão contar com mobiliários adequados e uma bancada com pia, sendo essa uma exigência mínima para esses ambientes. Além disso, devem conter instalações sanitárias próprias, completas, suficientes e adaptadas; um espaço ao ar livre para atividades físicas e lúdicas (BRASIL, 2002).

Além do espaço físico e próprio para a classe hospitalar, o atendimento poderá ser desenvolvido na enfermaria, no leito ou no quarto de isolamento, observando as restrições impostas por sua condição clínica. Os alunos a serem atendidos serão aqueles cujo estado de 


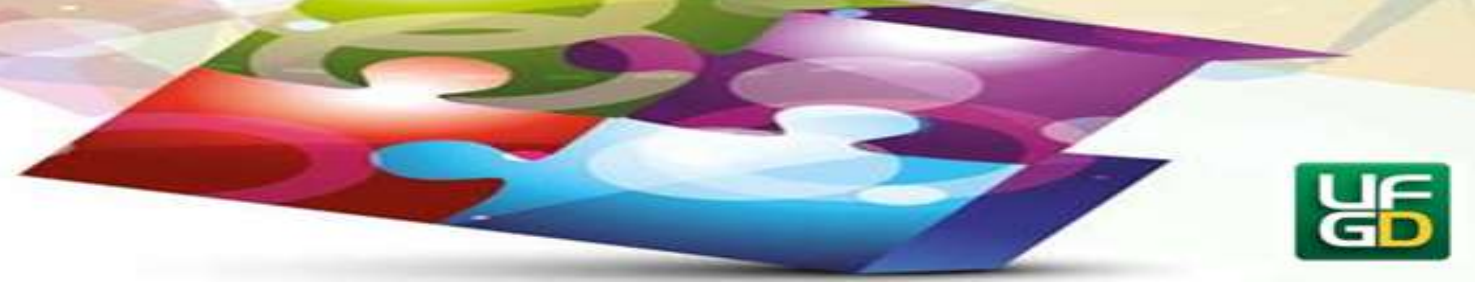

saúde o dificulta de frequentar a escola regular temporária ou permanentemente, respeitando suas capacidades e necessidades educacionais especiais individuais (BRASIL, 2002).

Sempre que possível, poderão ser disponibilizados recursos audio-visuais como computadores em rede, televisão, vídeos, máquina fotográfica, filmadora, entre outros, para uma adequada produção do planejamento e desenvolvimento das aulas, provendo e garantindo seu acesso escolar, o que propiciará as condições mínimas de aprendizado (BRASIL, 2002).

Sobre as questões estruturais, Fonseca (2002) aponta que não há um espaço adequado e exclusivo para esse trabalho pedagógico e que há falta de recursos materiais como equipamentos tecnológicos e acesso a internet. No mesmo sentido a pesquisa de Schmengler, Freitas e Pavão (2018) pontua que a acessibilidade é precária, de modo que faltam algumas adequações arquitetônicas como rampas, piso tátil, banheiros acessíveis, além de um déficit no que tange a tecnologias assistivas para uso com os alunos atendidos.

Quanto aos aspectos pedagógicos, orienta-se um processo de desenvolvimento e construção dos conhecimentos correspondentes à Educação Básica, mediante ação integrada e flexibilizada aos serviços de saúde, contribuindo com a promoção de saúde e ao melhor retorno ou continuidade dos estudos pelos educandos envolvidos (BRASIL, 2001a; 2002).

Fonseca (2002) indica que 38\% das classes hospitalares investigadas utilizam a metodologia baseada na Lei de Diretrizes e Bases da Educação Educacional (BRASIL, 1996); 24\% têm sua metodologia norteada pela Política de Educação Especial (BRASIL, 1994; 2001a); $22 \%$ dispõem de diretrizes específicas que fundamentam o atendimento escolar no ambiente hospitalar. Destaca ainda que $63 \%$ das classes hospitalares buscam dar continuidade no ensino dos conteúdos da escola regular de cada aluno hospitalizado (FONSECA, 2002).

Segundo a autora, as classes hospitalares implantadas funcionavam de formas variadas, indicando carência de recursos para o desenvolvimento das atividades, no entanto, com um objetivo comum, a conscientização quanto à necessidade de continuidade nos estudos durante o período de internação (FONSECA, 2002).

Os profissionais que desejam atuar no espaço escolar hospitalar devem ter uma formação específica. Segundo o documento norteador o professor dessa modalidade de atendimento deve: 


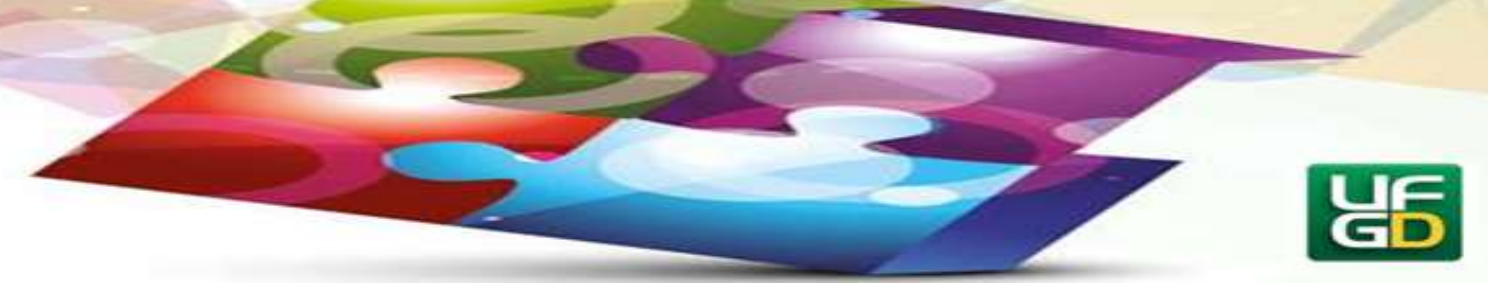

[...] ter a formação pedagógica preferencialmente em Educação Especial ou em cursos de Pedagogia ou licenciaturas, ter noções sobre as doenças e condições psicossociais vivenciadas pelos educandos e as características delas decorrentes, sejam do ponto de vista clínico, sejam do ponto de vista afetivo. Compete ao professor adequar e adaptar o ambiente às atividades e os materiais, planejar o dia-a-dia da turma, registrar e avaliar o trabalho pedagógico desenvolvido (BRASIL, 2002).

Refletindo acerca dessa orientação, verifica-se que há uma associação entre o profissional da Educação Especial e a habilidade de conhecer sobre "doenças" e "condições psicossociais" dos indivíduos, que seriam necessárias para fornecer o atendimento em classes hospitalares. Essa vinculação de sentidos permite suscitar o pensamento de Gaudenzi e Ortega (2016, p. 3065) de que "[...] o corpo com impedimentos não é necessariamente patológico". Assim, partindo desta noção, destaca-se como a própria atuação em ambientes hospitalares pode ser direcionada à produção de uma ideia de deficiência, considerando apenas sua condição de enfermidade.

A orientação do MEC segue em relação à integração com o sistema de saúde, abrangendo as condições clínicas que exigem educação em classe hospitalar, principalmente quanto: às dificuldades de locomoção; a imobilização parcial ou total; a imposição de horários para administração de medicamentos; os efeitos colaterais de determinados fármacos; as restrições alimentares; os procedimentos invasivos; o efeito de dores localizadas ou generalizadas e a indisposição geral decorrente de determinado quadro de adoecimento (BRASIL, 2002).

Diante das condições e limitações especiais, compete ao sistema educacional e serviços de saúde oferecerem assessoramento permanente ao professor, bem como acomodá-lo na equipe de saúde que coordena o projeto terapêutico individual. Além disso, o professor deve ter acesso aos prontuários dos usuários das ações e serviços de saúde sob atendimento pedagógico, seja para obter informações, seja para prestá-las do ponto de vista de sua intervenção e avaliação educacional (BRASIL, 2002).

Em que pesem as normativas de âmbito nacional, Paula, Zaias e Silva (2015) afirmam que nem todos os estados apresentam iniciativas relevantes no sentido de assegurar a efetividade do direito ao atendimento escolar hospitalar. Ressaltam que as políticas nessa área 


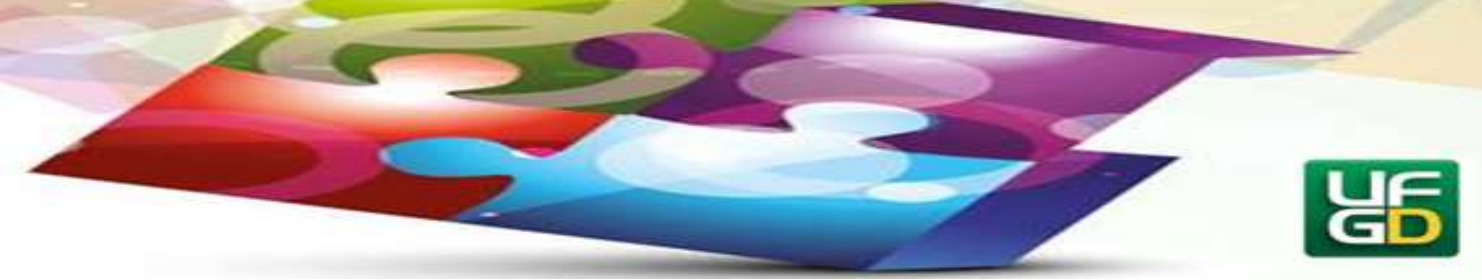

têm sido implementadas mediante convênios entre prefeituras, secretarias estaduais de educação ou saúde.

Considerando essa conjuntura, pode-se perceber a necessidade de maior articulação entre setores governamentais para implementação de uma política capaz de ampliar a rede de oferta dos atendimentos educaionais em hospitais. Além disso, para que a organização e funcionamento desses ambientes estejam de acordo com a legislação, demandam-se adequações estruturais, pedagógicas, disponibilidade de profissionais e recursos, sem os quais a promoção do ensino e aprendizagem em uma perspectiva inclusiva aos indivíduos atendidos torna-se comprometida.

\section{Considerações Finais}

As classes hospitalares foram criadas no Brasil, atreladas à Educação Especial, com o objetivo de garantir a continuidade dos estudos mesmo estando fora do ambiente escolar, trazendo os conteúdos trabalhados em sala de aula regular para o ambiente hospitalar. Assim, busca-se assegurar que o estudante tenha seu retorno ao ambiente escolar após a alta, sem prejuízos no aprendizado.

O MEC propõe que a educação em hospital se faça por meio da organização de classes hospitalares, assegurando oferta educacional não só ao PAEE, mas também, às crianças e adolescentes em situação de risco ao desenvolvimento, como é o caso da internação hospitalar, uma vez que a hospitalização pode gerar restrições às relações de convivência, às oportunidades sociais e interativas escolares e à exportação intelectual dos ambientes de vida social (BRASIL, 1994; FONSECA, 1999).

Essa relação estreita com a Educação Especial permite questionar a forma como tem ocorrido essa articulação. Conforme descrito pelos documentos político-normativos desse campo, a Educação Especial é responsável por organizar esses serviços em hospitais, sendo que os próprios docentes que ministrarão as aulas devem ter preferencialmente a formação nessa área. Não se questiona o mérito e a capacidade desses profissionais em atuar no campo hospitalar, mas problematiza-se a vinculação do atendimento educacional em hospitais à Educação Especial. Cabe indagar, portanto, se esse nexo decorre de resquícios do modelo 


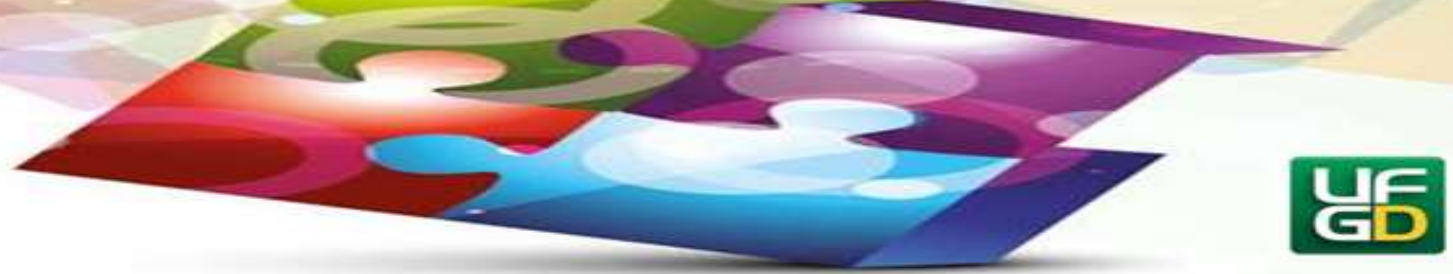

médico da deficiência existentes ainda em tempos de inclusão, em que a ideia de deficiência e doença/lesão/incapacidade continuam sendo associadas para fins educacionais.

Por fim, evidencia-se com o estudo que, embora a legislação brasileira reconheça o direito do indivíduo hospitalizado a receber esse tipo de atendimento pedagógico nos hospitais no período de internação, essa oferta ainda é muito restrita, não contemplando a todos que dela necessitam. Portanto, a pesquisa nessa área ainda se mostra como um campo aberto e fértil para novos estudos que venham a fortalecer as discussões e, possivelmente, ações que busquem ampliar a oferta de classes hospitalares no país.

\section{Referências}

BRASIL. Constituição da República Federativa do Brasil de 1988. Brasília, DF, 1988. Disponível em: http://www.planalto.gov.br/ccivil_03/constituicao/constituicao.htm. Acesso em 11 jun. 2020.

BRASIL. Lei no 9.394 de 20 de dezembro de 1996. Brasília, DF: Congresso Nacional, 1996. Disponível em: http://www.planalto.gov.br/ccivil_03/leis/19394.htm. Acesso em 11 jun. 2020.

BRASIL. Lei $n^{\circ}$ 13.716, de 24 de setembro de 2018. Brasília, DF: Congresso Nacional, 2018. Disponível em: http://www.planalto.gov.br/ccivil_03/_Ato2015-2018/2018/Lei/L13716.htm. Acesso em 11 jun. 2020.

BRASIL. Ministério da Educação. Classe hospitalar e atendimento pedagógico domiciliar: estratégias e orientações. Brasília, DF: MEC: SEESP, 2002. Disponível em: http://portal.mec.gov.br/seesp/arquivos/pdf/livro9.pdf. Acesso em: 11 jun. 2020.

BRASIL. Ministério da Educação. Diretrizes Nacionais para a Educação Especial na Educação Básica. [Brasília, DF]: MEC: SEESP, 2001a. Disponível em: http://portal.mec.gov.br/seesp/arquivos/pdf/diretrizes.pdf. Acesso em 11 jun. 2020.

BRASIL. Ministério da Educação. Política nacional de educação especial na perspectiva da educação inclusiva. [Brasília, DF]: MEC: SECADI, 2008. Disponível em: http://portal.mec.gov.br/index.php?option=com_docman\&view=download\&alias=16690politica-nacional-de-educacao-especial-na-perspectiva-da-educacao-inclusiva05122014\&Itemid=30192. Acesso em 11 jun. 2020.

BRASIL. Ministério da Saúde. Secretaria de Assistência à Saúde. Programa Nacional de Humanização da Assistência Hospitalar. Brasília, DF: Ministério da Saúde, 2001b. Disponível em: https://bvsms.saude.gov.br/bvs/publicacoes/pnhah01.pdf. Acesso em 11 jun. 2020. 


\section{HORIZONTES - REVISTA DE EDUCACATO}

E-ISSN: 2318-1540

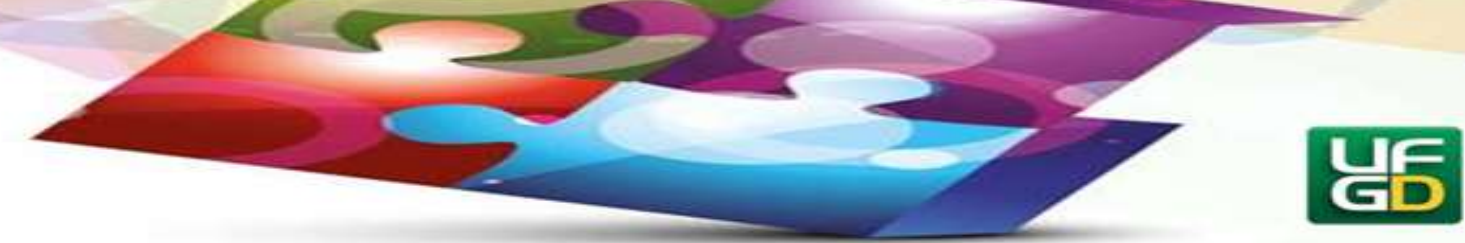

BRASIL. Secretaria de Educação Especial. Política Nacional de Educação Especial. Brasília, DF: MEC: SEESP, 1994. Disponível em:

https://midia.atp.usp.br/plc/plc0604/impressos/plc0604_aula04_AVA_Politica_1994.pdf. Acesso em: 11 jun. 2020.

CECCIM, R. B. Classe hospitalar: encontros da educação e da saúde no ambiente hospitalar. Pátio, ano 3, n. 10, p. 41-44, 1999. Disponível em:

http://www.cerelepe.faced.ufba.br/arquivos/fotos/84/classehospitalarceccimpatio.pdf. Acesso em 11 jun. 2020.

FONSECA, E. S. Classe hospitalar: ação sistemática na atenção às necessidades pedagógicoeducacionais de crianças e adolescentes hospitalizados. Temas sobre Desenvolvimento, v. 8, n. 44, p. 32-37, 1999. Disponível em:

http://www.gestaoescolar.diaadia.pr.gov.br/arquivos/File/pdf/classehospitalar_eneida.pdf. Acesso em 11 jun. 2020.

FONSECA, E. S. Classe hospitalar e atendimento escolar domiciliar: direito de crianças e adolescentes doentes. Revista Educação e Políticas em Debate, v. 4, n. 1, p. 12-28, jan./jul. 2015. Disponível em:

http://www.seer.ufu.br/index.php/revistaeducaopoliticas/article/view/31308/17042. Acesso em 11 jun. 2020.

FONSECA, E. S. Classe hospitalar: uma modalidade válida da educação especial no atendimento precoce? In: SEMINÁRIO BRASILEIRO DE PESQUISA EM EDUCACAO ESPECIAL, 5. Niterói, 1996. Anais [...]. Rio de Janeiro: UFF, 1996. p.37.

FONSECA, E. S. Implantação e implementação de espaço escolar para crianças hospitalizadas. Revista Brasileira de Educação Especial. v. 8, n. 2, p. 205-222, jul./dez. 2002. Disponível em:

http://www.cerelepe.faced.ufba.br/arquivos/fotos/124/implantaimplementaeneida.pdf. Acesso em 11 jun. 2020.

FONSECA, E. S. O Brasil e suas escolas hospitalares e domiciliares. In: SCHILKE, A. L.; NUNES, L. B.; AROSA, A. C. (org.). Atendimento Escolar Hospitalar: saberes e fazeres. Niterói: Intertexto, 2011, p. 81-90.

FONSECA, E. S.; ARAÚJO, C. C. A. C. A.; LADEIRA, C. B. Atendimento escolar hospitalar: trajetória pela fundamentação científica e legal. Revista Brasileira de Educação Especial, v. 24, edição especial, p. 101-116, 2018. Disponível em: https://www.scielo.br/pdf/rbee/v24nspe/1413-6538-rbee-24-spe-0101.pdf. Acesso em 11 jun. 2020.

FRANÇA, T. H. Modelo social da deficiência: uma ferramenta sociológica para emancipação social. Lutas Sociais, v. 17, n. 31, p. 59-73, jul./dez. 2013. Disponível em: https://revistas.pucsp.br/ls/article/view/25723/18359. Acesso em: 11 jun. 2020. 


\section{HORIZONTES - REVISTA DE EDUCACATO}

E-ISSN: 2318-1540

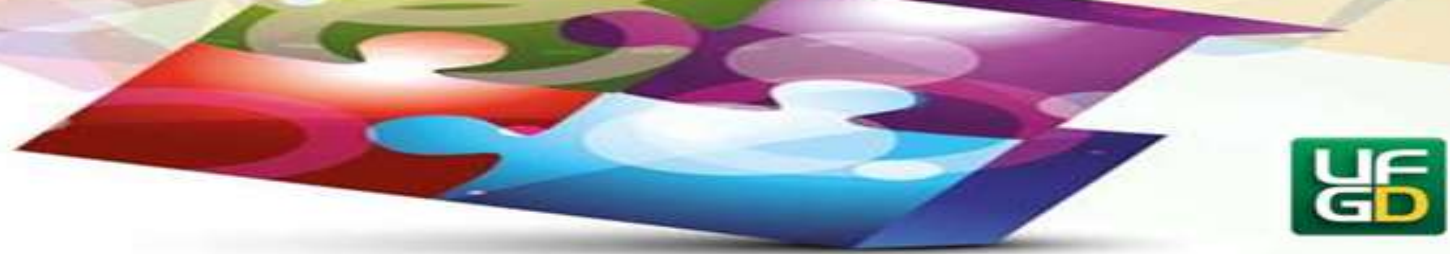

GAUDENZI, P.; ORTEGA, F. Problematizando o conteito de deficiência a partir das noções de autonomia e normalidade. Ciência e Saúde Coletiva, v. 21, n. 10, p. 3061-3070, 2016. Disponível em: https://www.scielo.br/pdf/csc/v21n10/1413-8123-csc-21-10-3061.pdf. Acesso em 11 jun. 2020.

GIL, A. C. Como elaborar projetos de pesquisa. 5. ed. São Paulo: Atlas, 2010.

GONÇALVES, A. G. MANZINI, E. J. Classe hospitalar: poesia, texto e contexto de crianças e adolescentes hospitalizados. Marília: ABPEE, 2011.

MANTOAN, M. T. E. Inclusão escolar: o que é? Por quê? Como fazer? São Paulo: Moderna, 2003.

MENDES, E. G. A radicalização do debate sobre inclusão escolar no Brasil. Revista Brasileira de Educação, v. 11, n. 33, p. 387-405, set./dez. 2006. Disponível em: https://www.scielo.br/pdf/rbedu/v11n33/a02v1133.pdf. Acesso em 11 jun. 2020.

NOZU, W. C. S. O poder da palavra: o discurso médico e o discurso social da deficiência e suas implicações para as políticas e práticas educacionais. In: NOZU, W. C. S.; BRUNO, M. M. G. (Orgs.). Educação especial e inclusão escolar: tensões, desafios e perspectivas. São Carlos, SP: Pedro \& João, 2014, p. 41-60.

OLIVEIRA, T. C. Um breve histórico sobre as classes especiais no Brasil e no mundo. In: CONGRESSO NACIONAL DE EDUCAÇÃO, 11, Curitiba. Anais [...]. Curitiba: PUC, 2013, p. 27685-27697. Disponível em: https://educere.bruc.com.br/ANAIS2013/pdf/9052_5537.pdf. Acesso em 11 jun. 2020.

OMS. Declaração de Alma-Ata. Alma-Ata, URSS, 1978. Disponível em: http://cmdss2011.org/site/wp-content/uploads/2011/07/Declara\%C3\%A7\%C3\%A3o-AlmaAta.pdf. Acesso em 11 jun. 2020.

PACCO, A. F. R.; GONÇALVES, A. G. Atendimento educacional hospitalar: revisão sistemática entre os anos de 2013 e 2018. Revista Educação Especial em Debate, v. 4, n. 7, p. 19-39, jan./jun. 2019a. Disponível em:

https://periodicos.ufes.br/reed/article/view/26517/18225. Acesso em 11 jun. 2020.

PACCO, A. F. R.; GONÇALVES, A. G. Contexto das classes hospitalares no Brasil: análise dos dados disponibilizados pelo censo escolar. Revista Diálogos e Perspectivas em Educação Especial. v. 6, n. 1, p. 197-212, jan./jun. 2019b. Disponível em:

http://revistas.marilia.unesp.br/index.php/dialogoseperspectivas/article/view/7536. Acesso em 11 jun. 2020.

PAULA, E. M. A. T. de.; ZAIAS, E.; SILVA, M. C. R. da. Políticas públicas em defesa do direito à educação: análise dos projetos de lei para expansão das classes hospitalares e atendimentos pedagógicos domiciliares no Brasil. Revista Educação e Políticas em Debate, v. 4, n. 1, p. 54-68, jan./jul. 2015. Disponível em: 


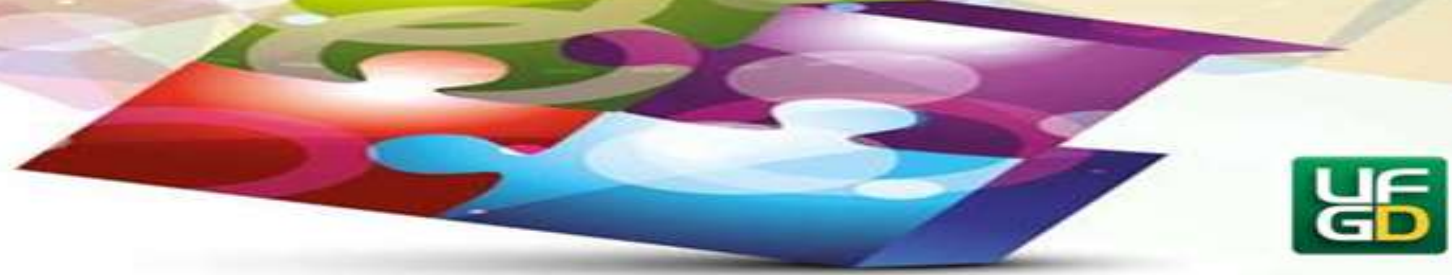

http://www.seer.ufu.br/index.php/revistaeducaopoliticas/article/view/31312/17044. Acesso em 11 jun. 2020.

SCHMENGLER, A. R.; FREITAS, S. N.; PAVÃO, S. M. O. Acessibilidade no atendimento educacional de alunos público-alvo da educação especial em uma classe hospitalar do estado do Rio Grande do Sul. Praxis Educativa, v. 13, n. 1, p. 128-144, jan./abr. 2018. Disponível em: https://www.revistas2.uepg.br/index.php/praxiseducativa/article/view/10281/6248. Acesso em 11 jun. 2020.

VASCONCELOS, S. Classe Hospitalar no mundo: um desafio à infância em sofrimento. In: REUNIÃO ANUAL DA SBPC, 57, Fortaleza, 2008. Anais [...]. Fortaleza, 2008. Disponível em: http://www.sbpcnet.org.br/livro/57ra/programas/CONF_SIMP/textos/sandramaiahospitalar.htm. Acesso em: 11 jun. 2020.

Enviado: 24/04/2020

Aceito: $11 / 06 / 2020$ 